\title{
Expression of the flagellin gene in Borrelia is controlled by an alternative $\sigma$ factor
}

\author{
Laila Noppa, ${ }^{1}$ Nils Burman, ${ }^{1}$ Ariadna Sadziene, ${ }^{2}$ Alan G. Barbour ${ }^{2}$ and \\ Sven Bergström ${ }^{1}$
}

Author for correspondence: Sven Bergström. Tel: +4690 176726. Fax: +4690112630.

\footnotetext{
1 Department of Microbiology, Umeå University, S-901 87 Umeå, Sweden

2 Departments of Microbiology and Medicine, University of Texas, Health Science Center at San Antonio, Texas 78284, USA
}

\begin{abstract}
The flagellin genes from six Borrelia species were cloned, sequenced and characterized at the molecular level. The flagellin genes of two relapsing fever Borrelia species, B. hermsii and B. crocidurae, three Lyme disease genomic species, B. burgdorferi, B. afzelii and B. garinii, and the avian borreliosis agent, $B$. anserina, were compared and showed an 85-93\% sequence identity to each other. Comparison of the fla genes from the different Lyme borreliosis spirochaetes revealed that they were 94-99\% identical. Nucleotide sequencing of the fla gene and primer extension on isolated mRNA from both $B$. hermsii (as transcribed in Escherichia coll) and B. burgdorferi (as transcribed in the natural host) identified the putative transcriptional start points, the ribosomebinding sites and the promoter regions of these genes. The deduced promoter of the Borrelia flagellin gene resembled neither the $\sigma^{70}$ promoter of prokaryotes, as seen for the genes for the outer-surface proteins $A$ and $B$ in Lyme disease Borrelia and the genes for the variable major proteins 7 and 21 of $B$. hermsii, nor the $\sigma^{28}$ consensus promoter region of motility genes from other bacteria. Instead, the promoter of the fla gene in Borrelia has most similarity to the bacteriophage SP01 $\sigma^{\mathrm{gp33}-34}$ promoter sequence of Bacillus subtilis.
\end{abstract}

Keywords: Borrelia, spirochaetal flagella, flagellin

\section{INTRODUCTION}

Spirochaetes, distinct from other bacteria in their morphology and motility, constitute a separate phylum of bacteria that are only remotely related to Gram-negative and Gram-positive bacteria (Woese, 1987). The genus Borrelia contains several major pathogenic groups of organisms. Among these are the relapsing fever borreliae, Lyme borreliosis borreliae, and the aetiological agent of avian spirochaetosis, $B$. anserina. The Lyme disease agent $B$. burgdorferi has recently been divided into different genomic species, including B. burgdorferi, $B$. garinii and $B$. afzelii (Baranton et al., 1992; Marconi \& Garon, 1992a; Canica et al., 1993).

The motility-promoting flagellar apparatus is a cell structure that spirochaetes have in common with other motile bacteria (Canale-Parola, 1978; Goldstein \& Charon, 1988; Charon et al., 1992). Unlike other bacterial

The EMBL accession numbers for the nucleotide sequences reported in this paper are $X 75200$ for $B$. burgdorferi HB19, X75202 for B. afzelii ACAl, X75203 for B. garinii Ip90, X75204 for B. crocidurae and X75201 for $B$. anserina. flagella, those of the spirochaetes are situated within the periplasm and are referred to as periplasmic flagella. Flagella are inserted at each end of the protoplasmic cylinder and extend along its axis, overlapping each other in the middle. The flagella of borreliae are different from those of other spirochaetes in that they are not surrounded by an outer sheath layer (Holt, 1978), and in B. burgdorferi the flagella are comprised of a single flagellin protein (Barbour et al., 1986).

Immunochemical analysis of borreliae has revealed that the flagellin is one of the immunodominant antigens during infection in both humans and animals. Antibodies against the flagellin appear early in the sera of most patients and are prominent during all stages of the disease (Barbour, 1984b; Craft et al., 1984, 1986). Therefore, the flagellins in Borrelia have been studied extensively with the purpose of developing diagnostic tools for Lyme borreliosis (Malloy et al., 1990; Marconi \& Garon, 1992b; Picken, 1992; Rosa \& Schwan, 1989; Rosa et al., 1991). Previously, it has been shown that an aflagellate mutant of $B$. burgdorferi had reduced ability to penetrate human endothelial cell layers in vitro (Sadziene et al., 1991), 
Table 1. Oligonucleotides used for PCR, screening of plasmid gene libraries, nucleotide sequencing and primer extension analysis

\begin{tabular}{|lccl|}
\hline Oligonucleotide & $\begin{array}{c}\text { Strain } \\
\text { of origin }\end{array}$ & Position* & \multicolumn{1}{c|}{ Sequence 5' to 3' } \\
\hline FB1 & B31 & $-73--53$ & GTGCTATTCTTTTTAACAGGC \\
FB2 & B31 & $1-25$ & ATGATTATCAATCATAATACATCAG \\
FB3 & HS1 & $88-105$ & TCTATGCCCACTAGAAAG \\
FB4 & B31 & $116-135$ & GCCAGCAGCATCATCAGAAG \\
FB5 & B31 & $438-459$ & AACAGCTGAAGAGCTTGGAATG \\
FB6 & B31 & $572-593$ & AAAAGATTTCAACATTAGCTG \\
FB7 & B31 & $\mathbf{9 8 9 - 1 0 1 3}$ & TTATCTAAGCAATGACAAAACATAT \\
FB8 $†$ & B31 & $1157-1176$ & CCCTACTCAAAGCAAACTCC \\
\hline
\end{tabular}

* All positions are derived from the B. burgdorferi B31 fla gene sequence in Fig. 2.

† Oligonucleotide FB8 is located downstream of the fla gene and therefore has no match in Fig. 2.

indicating that the flagella have a role in the invasion of human tissue.

The genes encoding the flagellin polypeptides, $\operatorname{fla} A$ and $f a B$, of several spirochaetes, including Spirocbaeta aurantia, Treponema pallidum and Serpulina byodysenteriae, have been cloned and sequenced (Brahamsha \& Greenberg, 1989; Parales \& Greenberg, 1993; Isaacs \& Radolf, 1990; Isaacs et al., 1989; Koopman et al., 1992, 1993). The fla $A$ gene' products constitute the flagellar sheath layer and have the unique characteristic, unlike flagellins of other eubacteria, of an N-terminal signal peptide. These flagellins show no sequence homologies with those of eubacteria. However, the core polypeptides, encoded by the $f a B$ genes lack a signal peptide and share homologies with the flagellins of Salmonella typhimurium and Escherichia coli. The expression of flagellin and chemotactic genes of many eubacteria is controlled by alternative $\sigma$-factors (Arnosti \& Chamberlin, 1989; Helmann, 1991). In the enteric bacteria, the promoter sequences preceding the flagellin genes are very similar to the Bacillus subtilis $\sigma^{28}$ recognition site (Helmann \& Chamberlin, 1987; Helmann, 1991).

In this study, we have analysed and compared the flagellin genes and gene products from different representatives of six genomic Borrelia species. The transcriptional start points in two species, $B$. burgdorferi and $B$. bermsii, have been determined. We have also analysed the upstream control regions of the respective $f l a$ genes and compared them to those of other eubacterial flagellin genes.

\section{METHODS}

Bacterial strains and plasmids. The Lyme borreliosis strains investigated, B31, HB19, ACAI and Ip90 were chosen to represent a wide geographical distribution and to include one of each of the three newly defined genomic species, B. burgdorferi, B. garinii and B. afzelii (Marconi \& Garon, 1992a; Baranton et al., 1992; Canica et al., 1993). B. burgdorferi is represented by the North American reference strain B31 (ATCC 35210) isolated from an Ixodes scapularis tick, and strain $\mathrm{HB} 19$, a blood isolate from a patient with Lyme disease in Connecticut, USA. B. afzelii strain ACAI, isolated from a patient with acrodermatitis chronica atrophicans, was obtained from Dr Eva Asbrink
(Södersjukhuset, Stockholm, Sweden; Åsbrink et al., 1984), and B. garinii strain Ip90, isolated from an Ixodes persulcatus tick, was kindly provided by Drs E. I. Korenberg and V. N. Kryuchechnikov of the Gamaleya Institute, Moscow, Russia. B. bermsii strain HS1, serotype C (ATCC 35209), B. crocidurae and B. anserina were obtained from the strain collection of Alan G. Barbour. Plasmids pBR322 and pUC18 were purchased from Bio Labs, Finnzymes.

Media and growth conditions. All Borrelia species were cultivated in BSKII medium at $34^{\circ} \mathrm{C}$ (Barbour, 1984a). The cells were harvested at the mid-exponential phase and prepared for DNA or protein analysis as described previously (Barbour, 1988; Barbour \& Garon, 1987; Howe et al., 1985; Jonsson et al., 1992). The E. coli strains DH5 and DH5 (Life Technologies) were used for propagation of recombinant plasmids.

Cloning of the flagellin gene from four different Borrelia species. A flagellin-bearing clone originating from B. burgdorferi HB19 was constructed as follows. An oligonucleotide representing a conserved sequence (FB4 in Table 1), of the previously sequenced $f a$ genes of B. burgdorferi GeHo and B31 (Gassmann et al., 1989a, 1991; Wallich et al., 1990), was used to identify $f a$-containing clones in a $\lambda$-fixII library of genomic DNA from $B$. burgdorferi HB19. A $5.0 \mathrm{~kb} \mathrm{Bg/II}$ fragment containing the complete $f a$ gene was subcloned into pBR322 to yield pASF01.

To clone the flagellin genes from $B$. anserina and B. crocidurae, plasmid gene libraries were constructed by partial HindIII digestion of total borrelial DNA (Jonsson et al., 1992). The oligonucleotides FB2, FB5 and FB6 were designed and synthesized from the published $f a$ sequences (Table 1). The oligonucleotides were end-labelled with $\left[\gamma^{32} \mathrm{P}\right] \mathrm{dATP}$ and used for screening libraries as described by Maniatis et al. (1982). The hybridization was performed at moderate stringency at $55^{\circ} \mathrm{C}$, as some differences in the nucleotide sequences of the different species were expected. Plasmids obtained were named pLNA01 (B. anserina), pLNC01 and $\mathrm{pLNCO} 2$ (B. crocidurae). Oligonucleotide FB5 was used to detect pLNA01, which had a $5.8 \mathrm{~kb}$ insert containing the complete fla gene. Oligonucleotide FB2 was used to detect $\mathrm{pLNC01}$, which covers the $5^{\prime}$ part of the fla gene, while pLNCO2 covers the middle part and was detected with FB5.

The last $3^{\prime}$ part of the flagellin gene from $B$. crocidurae was constructed by cloning a PCR fragment, which was amplified using the FB5 and FB7 oligonucleotides as primers. Amplification of DNA was according to the manufacturer's instructions 
(a)

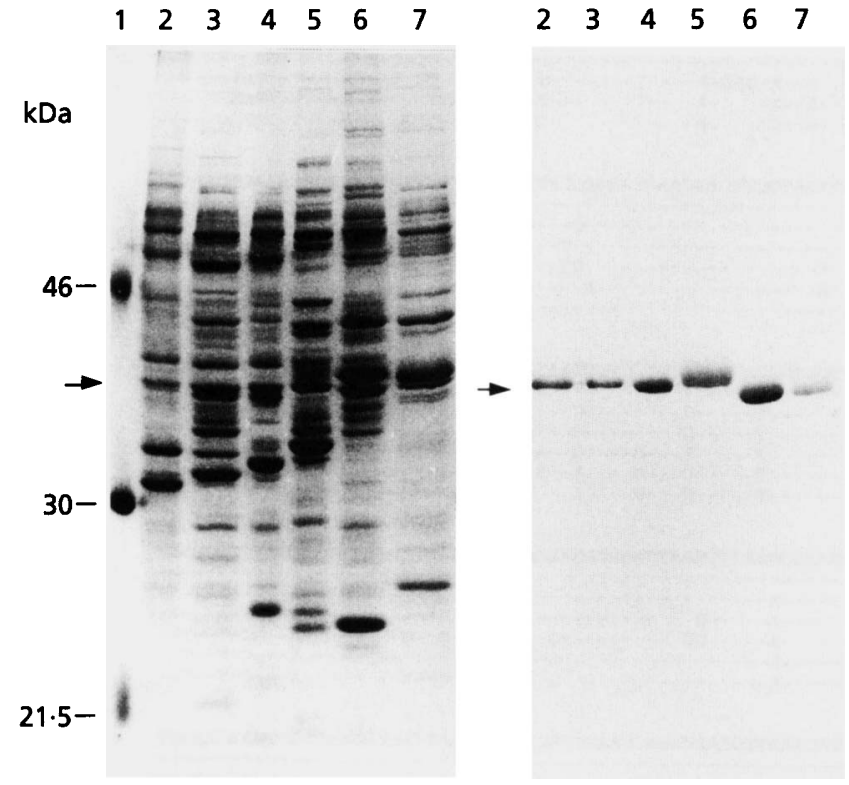

Fig. 1. SDS-PAGE $(12.5 \%$ acrylamide) and Western blots of whole-cell lysates of Borrelia spirochaetes. (a) Coomassiebrilliant-blue-stained protein gel of Borrelia species: lanes: $2, B$. burgdorferi B31; 3, B. afzelii; 4, B. garinii; 5, B. crocidurae; $6, B$. hermsii; $7, B$. anserina. Molecular mass standards are in lane 1. (b) Western blot analysis of the same Borrelia species using anti-flagellin monoclonal antibody H9724. Lanes 2-7, as for (a). The flagellin proteins are arrowed.

(Perkin-Elmer Cetus). The first five cycles of denaturation were done at $94^{\circ} \mathrm{C}$ for $2 \mathrm{~min}$, annealing at $45^{\circ} \mathrm{C}$ for $1 \mathrm{~min}$, and elongation at $72^{\circ} \mathrm{C}$ for $1 \mathrm{~min}$. In the next 30 cycles, the denaturation time was shortened to $30 \mathrm{~s}$ and the annealing temperature was raised to $55^{\circ} \mathrm{C}$, otherwise the conditions were the same. Taking advantage of the $3^{\prime}$ adenine overhang left by many Taq DNA polymerases, we were able to ligate fragments containing the last part of the fla gene into the pT7blue T-vector (Novagene), containing compatible single thymine overhangs. Three positive clones were isolated, each originating from different PCR reactions, and were designated pLNC03, pLNC04 and pLNC05. The same approach was used to clone the whole fla gene from B. burgdorferi strain Ip90. FB1 and FB8 oligonucleotides, located upstream and downstream, respectively, of the $f l a$ gene, resulted in plasmid constructs of pLNI01, pLNI02 and $\mathrm{pLNI03}$. The flagellin gene of $B$. bermsii was also cloned by PCR. An oligonucleotide primer, located upstream of the gene, was designed: 5'-T'T'TGAAT'TCACAGCGACAAAACA-3' containing a mismatch creating an EcoRI site (underlined). The second primer, 5'-ATAAGGATCCAT'TAAAAGACCC-3', located downstream of the gene, contains a mismatch creating a Bam HI site (underlined). This enabled us to digest the PCR product with the same enzymes and directly ligate it into the corresponding sites of pUC18. A positive clone was obtained and named $\mathrm{pLNH} 01$. The cloned gene was further characterized by restriction enzyme analysis and mini plasmid preparations (Saunders \& Burke, 1990) followed by nucleotide sequencing (Sanger et al., 1977).

Protein preparation, SDSPAGE and Western blotting. Extraction of proteins from four different Borrelia species was performed as described before (Jonsson et al., 1992). Protein samples $(10 \mu \mathrm{g}$ per well) were analysed by SDS-PAGE $(12.5 \%$ acrylamide) (Maniatis et al., 1982). Molecular mass standards ranging in size from 14.4 to $94 \mathrm{kDa}$ were obtained from Pharmacia. The gels were either fixed and stained by Coomassie brilliant blue (Sigma), or processed for immunoblotting. The proteins were electrophoretically transferred to a Fluorotrans transfer membrane (Pall Europe) for $45 \mathrm{~min}$ at $0.8 \mathrm{~mA} \mathrm{~cm}$. The blocking procedure, incubation and visualization of the bound antibodies were performed as described previously (Jonsson et al., 1992). Monoclonal antibody H9724, which has a murine immunoglobulin G2a isotype and is specific for Borrelia flagellins (Barbour et al., 1986), was used.

DNA techniques. Restriction enzymes, T4 DNA ligase (Bio Labs, Finnzymes), reverse transcriptase (Pharmacia, and Life Science), Sequenase (USB), and the T7 sequencing kit (Pharmacia) were used as recommended by the manufacturers. Borrelia genomic DNA was isolated as described previously (Barbour, 1988; Barbour \& Garon, 1987; Howe et al., 1985).

Isolation of mRNA and primer extension. A plasmid, pLNH01, containing the $f a$ gene from $B$. bermsii was introduced into $E$. coli $\mathrm{DH} 5 \alpha$ cells, and total mRNA was prepared as described previously (von Gabain et al., 1983). The isolated mRNAs were subjected to primer extension in an in vitro reaction with a specific ${ }^{32}$ P-labelled oligonucleotide primer FB3 (Table 1). The oligonucleotide was end-labelled using $\mathrm{T} 4$ polynucleotide kinase (Pharmacia) and $\left[\gamma^{-32} \mathrm{P}\right] \mathrm{ATP} \quad\left(>5 \mathrm{kCi} \mathrm{mmol}^{-1}\right.$; $185 \mathrm{TBq} \mathrm{mmol}^{-1}$, Amersham) as described by Maniatis et al. (1982). AMV reverse transcriptase (Pharmacia) was used in DNA synthesis as described by Göransson et al. (1989). Total RNA from B. burgdorferi HB19 was isolated (Burman et al., 1990) and subjected to primer extension with the use of primer FB4 (Table 1) according to Hamlyn et al. (1981). In both cases, only full-length extension products were synthesized, and the sizes of the transcripts were compared with a DNA sequence ladder (Sanger et al., 1977), directed by the same oligonucleotide primers, using plasmids pLNH01 and pASF1 as templates for $B$. bermsii $\mathrm{HS} 1$ and $B$. burgdorferi $\mathrm{HB} 19$, respectively.

Nucleotide sequence analysis. Single-stranded DNA from the flagellin genes of $B$. hermsii HS1, B. burgdorferi B31 and B. af zelii ACAI was obtained by asymmetric PCR (Gyllensten \& Erlich, 1988) using $10 \mathrm{ng}$ of the double-stranded PCR products that were purified from agarose gels (Zhu et al., 1985). The final concentration of the limiting primer was $0.015 \mathrm{mM}$, and the concentration of the primer in excess was $1.0 \mathrm{mM}$. The running conditions for the PCR were as described above. Single-stranded DNA from the asymmetric PCR reactions was precipitated and sequenced directly using the dideoxy chain-terminating method (Sanger et al., 1977). The same method was used to sequence the double-stranded recombinant plasmids containing the complete or partial fragments of the fla genes (described in detail above) from $B$. anserina, $B$. crocidurae, B. bermsii (HS1), B. burgdorferi (HB19) and B. garinii (Ip90). The nucleotide sequences of both strands were determined partly with the primer oligonucleotides listed in Table 1 and partly with other oligonucleotides derived from the sequence data of Gassmann et al. (1989a). Sequences were assembled using GENEus (Harr et al., 1986) software for VAX computers (DEC). Further nucleotide sequence and protein sequence analyses were performed using the University of Wisconsin GCG sequence analysis software for VAX computers.

Phylogenetic analysis. DNA phylogeny predictions of the $f a$ gene between the different species were performed by the parsimony method in the PAUP program for the Apple MacIntosh computer (Swofford, 1990). Support for these groups was assessed using bootstrap analysis (1000 replicates), which is included in the PAuP package. The resulting 

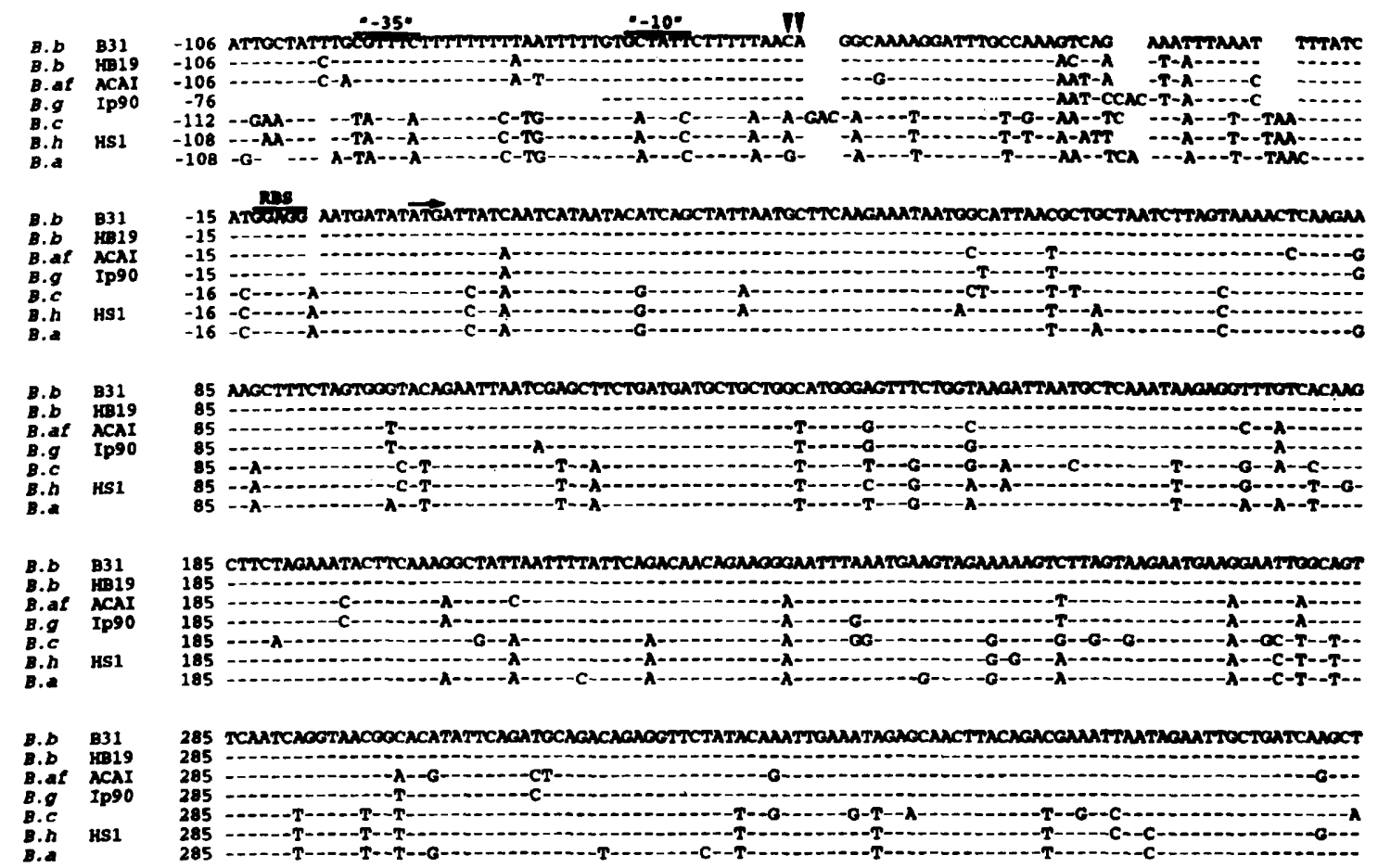

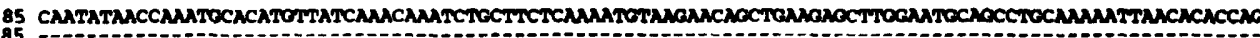
385

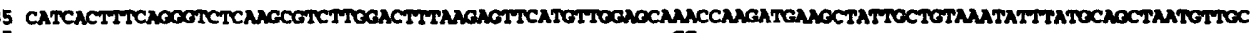
485 - 485 -

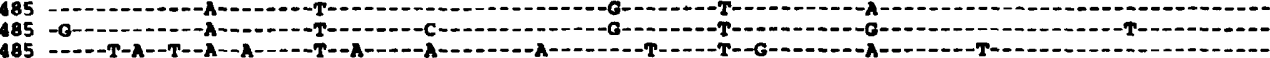
485

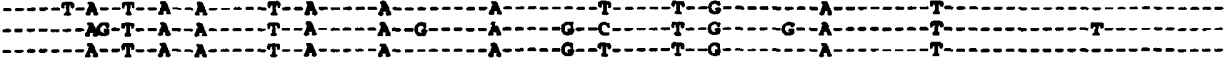

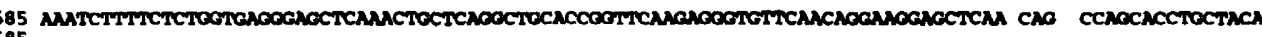
585 A 585 (1) 585 - 585 -

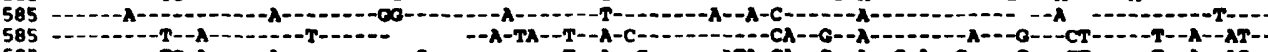
85 - C C C

$\begin{array}{ll}\text { B.b } & \text { B31 } \\ \text { B.b } & \text { HB19 }\end{array}$

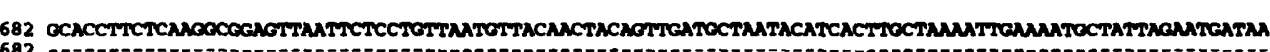
682 682 -G-

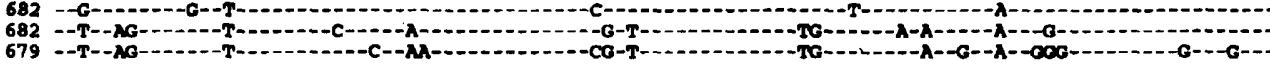

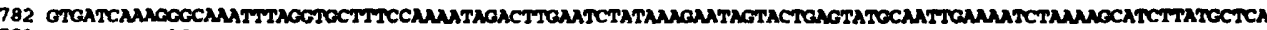
782 782 - 78 782 - 782 -

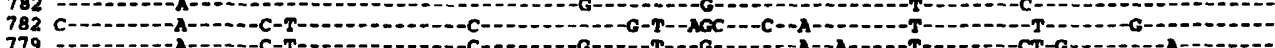
779 - 779

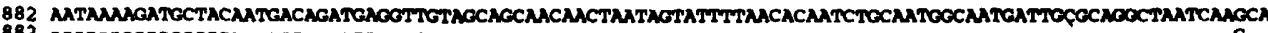
B82 a

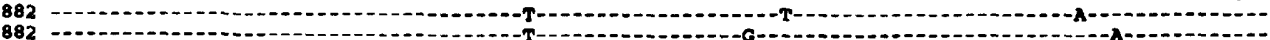

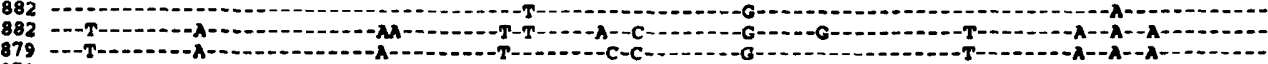

B.b B31 982 TTCCCCMTATCTTMTGTCATTCCTTAGATM

Fig. 2. For legend see facing page. 
dendrogram had the same clustering order as that obtained from pairwise alignments performed by the program PILEUP in GCG.

\section{RESULTS AND DISCUSSION}

\section{The Borrelia flagellin protein}

Whole-cell protein extracts prepared from $B$. burgdorferi B31, B. afzelii, B. garinii, B. crocidurae, B. hermsii and $B$. anserina were separated by $12.5 \%$ SDS-PAGE (Fig. 1a). The separated proteins were subjected to Western blot analysis using the Borrelia-specific anti-flagellin monoclonal antibody H9724. For all strains, a protein of about $40 \mathrm{kDa}$ bound the antibody (Fig. 1b). The small differences in sizes between the flagellin proteins from the different strains are in accordance with the respective $f l a$ gene products deduced from the nucleotide sequence (see below).

\section{Nucleotide sequence analysis of flagellin genes}

The $f l a$ genes of the two relapsing fever species, B. bermsii and $B$. crocidurae, of the Lyme borreliosis genomic species, B. afzelii, B. burgdorferi and B. garinii, and of the avian borreliosis isolate $B$. anserina were sequenced. The sequences and their alignments are shown in Fig. 2. An overall sequence identity of $85-86 \%$ was seen when comparing the $f l a$ gene of the Lyme borreliosis genomic species with the two relapsing fever species and $B$. anserina. The Lyme borreliosis Borrelia species showed 94-95\% identity to each other. The $f l a$ sequences of $B$. burgdorfer $i$ strains HB19 and B31 were $>99 \%$ identical. The $f a$ sequence of $B$. anserina was more similar to the sequences from the two different relapsing fever species than to the Lyme borreliosis genomic species: $91 \%$ to $B$. crocidurae, $93 \%$ to $B$. bermsii, while only $86-88 \%$ identical to the different Lyme borreliosis genomic species. Within the relapsing fever species, $B$. bermsii and $B$. crocidurae, the identity was $90.5 \%$. The $f l a$ gene of $B$. crocidurae is the first sequenced gene of this species.

We also compared the flagellin gene sequences of $B$. burgdorferi $\mathrm{B} 31$ and $B$. bermsii HS1 to the previously published sequences of these strains (Gassmann et al., 1989a; Wallich et al., 1990; Picken, 1992). One base pair difference in the B. burgdorferi B31 fla gene was seen at position 539 (Fig. 2): Gassmann et al. (1989a) have reported a $C$ in this position, where our sequence has an A. The $B$. hermsii $f l a$ sequence was identical to the previously published sequence.

Further analysis of the nucleotide sequences revealed that the upstream control regions were similar in all six genomic species investigated, which indicates that all six Borrelia species use similar regulatory signals. A putative ribosome-binding site, 5'-GGAGG-3', was observed $13 \mathrm{bp}$ upstream of the initiation codon, ATG, in all of the strains sequenced by us (Fig. 2).

From the sequence data obtained, we conclude that the $f a$ genes from different Borrelia species show a high degree of similarity. However, some significant differences were seen, especially in positions 606-614 in B. bermsii and $B$. anserina, and positions $613-618$ in $B$. crocidurae, where a duplication of $9 \mathrm{bp}$ or a deletion of $6 \mathrm{bp}$, respectively, has occurred. These regions of sequence heterogeneity were particularly useful for species determination in Borrelia spirochaetes found in seabirds and Ixodes uriae ticks (Olsén et al., 1993). They may also be of practical benefit for the construction of oligonucleotide primers for PCR diagnosis of Lyme, avian, and relapsing fever borreliosis (Picken, 1992).

\section{Determination of the transcriptional start point of fla}

To locate the fla promoter, the transcriptional start site of the $f l a$ gene of $B$. hermsii HS1 was determined from a $f a$ gene expressed in E. coli. The transcriptional start point of the $f a$ gene of $B$. burgdorferi HB19 was determined on mRNA prepared directly from whole cells of Borrelia bacteria. The transcriptional initiation sites of $B$. bermsii HS1 and B. burgdorferi HB19 fla genes were shown to be an $A$ at base 60 and a $C$ at base 57 upstream of the AUG, respectively (Fig. 2). This is consistent with the findings of Gassmann et al. (1991) using strain GeHo. Since we analysed the transcriptional start points from Borrelia as well as from E. coli mRNA, the results suggest that the $f a$ gene expression uses the same promoter sequence regardless of whether the $f l a$ gene is expressed in Borrelia or in E. coli.

All $f a$ genes that were sequenced had similar regulatory sequences upstream of the structural genes. Of particular interest was the apparent lack of the typical consensus $\sigma^{70}$ promoter recognition site found in other sequenced Borrelia genes, i.e. the osp $A B$ operons of $B$. burgdorferi, $B$. afzelii and $B$. garinii, or the vmp genes of $B$. hermsii (Bergström et al., 1989; Jonsson et al., 1992; Burman et al., 1990). Conserved elements upstream of the $f a B$ genes of Treponema pallidum and $T$. phagedenis, and of the flagellar and chemotaxis operons in E. coli and Salmonella typhimurium, have been found to be similar to the consensus sequences that determine the $\sigma^{28}$ function in Bacillus subtilis (Pallesen \& Hindersson, 1989; Champion et al., 1990; Limberger et al., 1992; Helmann, 1991). Earlier reports concerning the promoter sequences of the fla gene in Borrelia have suggested that a Pribnow box is located at positions -19 to -13 (Wallich et al., 1990), while Gassmann et al. (1991) suggested that a presumptive

Fig. 2. Comparison of nucleotide sequences of the flagellin genes from $B$. burgdorferi $(B . b) B 31$ and $H B 19, B$. afzelii $(B$. af), B. garinii (B. g), B. crocidurae (B. C), B. hermsii (B. h) HS1 and B. anserina (B. a). The flagellin sequence of $B$. burgdorferi $B 31$ is shown in the top line. Hyphens indicate homology between the fla genes of the different species and strains, capital letters indicate differences, and gaps indicate missing (or inserted) bases. The ' $-10^{\prime}$ ' and ' $-35^{\prime}$ ' regions of the promoter and the ribosome-binding sites (RBS-Shine-Dalgarno sequences) are overlined. The transcriptional startpoints, as determined by primer extension (data not shown), are indicated by arrowheads, while the ATG start codon is marked with an arrow. 
Table 2. Comparison of the promoter region preceding the fla genes in Borrelia, Leptospira and Treponema with Bacillus subtilis $\sigma^{\text {gp } 33-34}$ and $\sigma^{28}$ recognition sequences

\begin{tabular}{|c|c|c|c|c|c|}
\hline \multirow[t]{3}{*}{ Organism } & \multirow[t]{3}{*}{ Gene } & \multicolumn{3}{|c|}{ Promoter sequence } & Reference/source \\
\hline & & \multicolumn{3}{|c|}{ Bacillus subtilis, phage SP01* } & \\
\hline & & CGTTAG & & GATATT & Johnson et al. (1983) \\
\hline B. burgdorferi $\mathrm{B} 31$ & $f l a$ & CGTTTC & tttttttaattttgt & GCTATT & Gassmann et al. (1989a) \\
\hline B. burgdorferi $\mathrm{HB} 19$ & $f l a$ & CGTTTC & tttttttaaattttgt & GCTATT & This study \\
\hline B. afzelii ACAI & $f l a$ & CGTTTC & ttttttttatttttgt & GCTATT & This study \\
\hline B. garinii Ip90 & $f a$ & TTC & tttttttaattttgt & GCTATT & This study \\
\hline B. crocidurae & $f a$ & АTTTAT & tett ttcttgtttttgt & GATATC & This study \\
\hline B. bermsii HS1 & $f a$ & ATTTAT & tttt ttcttgttttgt & GATATC & This study, Picken (1992) \\
\hline B. anserina & $f a$ & ATTTAT & tttt tcttgtttttgt & GATATC & This study \\
\hline L. borgpetersenii & $f a B$ & CGCCTG & gtctgtcaggtggtctg & AATATT & This study, Mitchison et al. (1991) \\
\hline \multirow[t]{3}{*}{ S. byodysenteriae } & $\mathrm{AlaB} 2$ & AGTTAG & attgtcggaatacct & TAAATT & This study, Koopman et al. (1993) \\
\hline & & \multicolumn{3}{|c|}{ Bacillus subtilis† } & \\
\hline & & CTAAA & $\mathrm{N}_{16} \quad \mathrm{CC}$ & GATAT & Gilman et al. (1981) \\
\hline T. pallidum & faB2 & CTCAA & gtgcacccggcgtatt $\mathrm{CC}$ & GATAC & Pallesen \& Hindersson (1989) \\
\hline T. pallidum & flaB1 & CTCAA & gtcctttccgttttt $\mathrm{CC}$ & GATTT & Champion et al. (1990) \\
\hline$T$. phagedenis & flaB2 & СТTAA & gtgttttttccgccat $\mathrm{CC}$ & GATAC & Limberger et al. (1992) \\
\hline
\end{tabular}

* E $\sigma^{\mathrm{gp33-34}}$ promoter sequence of bacteriophage SP01 of $B$. subtilis.

$\dagger$ B. subtilis $\mathrm{E} \sigma^{28}$ consensus promoter sequence.

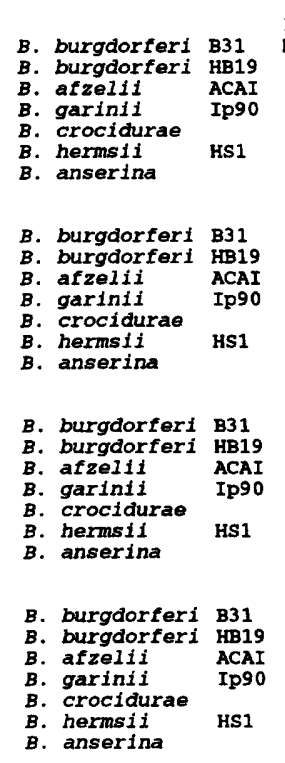

1 MIINHNTSAINASRIGINAANL SKTOEKLSSGYRIIRA

51

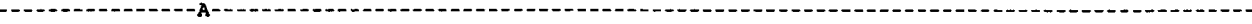
101 101

TYSDADRGSIQIEI EQLTDEINRIADQAQYNQMHLSNKSASQNVRTAEELGMQPAKINTPASLSGSQASWTLRVHVGANQDEAIAVNIYAANVANLFSG Th -1
-1 201 EGAQTAQAAPVQEGVQQEGAQQ PAPATAPSQGGVNSPVNVTTTVDANTSLAKIENAIRMISDQRANLGAFQNRLESIKNSTEYAIENLKASYAQIKDAT EGA

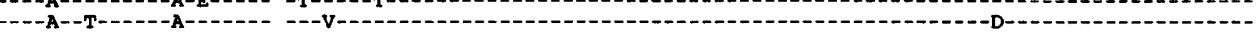

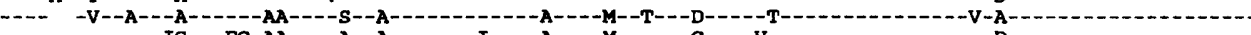
-2 300 MTDEVVAATTNSILTQSAMAMIAQANQVPQYVLSLLR (-0.--

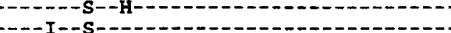
burgdorferi B31 sequence. Hyphens indicate homology
Fig. 3. Comparison of deduced amino acid sequences of the flagellin proteins from B. burgdorferi, B. afzelii, $B$. garinii, B. crocidurae, B. hermsii HS1 and B. anserina. All sequences are compared and aligned with the $B$. between the strains, capital letters indicate differences, and gaps indicate missing amino acids. control region that exhibited a closer homology to $\sigma^{\mathbf{7 0}}$ promoters of $E$. coli could be found. However, our sequence data for the fla gene promoter region did not show any sequence similarity in the $-10,-35$ or other regions upstream of the consensus sequences for $\sigma^{70}$, $\sigma^{54}-, \sigma^{32}-$ or $\sigma^{28}$-like promoters. Instead, the putative promoters for the $f l a$ genes of $B$. burgdorferi and $B$. bermsii most closely resembled the ' -10 ' and ' -35 ' regions of the $\sigma^{\text {gp33-34 }}$ promoter sequence of the late genes of bacteriophage SP01 of Bacillus subtilis (Table 2) (Johnson et al., 1983; Costanzo et al., 1984). The matches with the respective putative promoters are indicated in Fig. 2 and summarized in Table 2. The ' -10 ' element is almost identical (5 out of 6 nucleotides) to the consensus -10 region of the late SP01 genes, whereas the ' -35 ' element has only 4 out of 6 nucleotides or 3 out of 6 nucleotides identical to the consensus sequence for B. burgdorferi and $B$. bermsii, respectively. Also, the putative promoter 
regions of B. afzelii, B. garinii, B. crocidurae and B. anserina most closely resemble the SP01 promoter (Table 2).

In Treponema spp., the flagellum is composed of a core protein encoded by the $f a B$ gene, surrounded by a sheath protein encoded by the fla $A$ gene (Norris et al., 1993). The promoter sequences of the Treponema fla $A$ genes are similar to the consensus $\sigma^{70}$ promoter, while the $f a B$ genes appear to use a $\sigma^{28}$-like promoter as for other eubacterial motility genes (Table 2). Recently, the $f a B$ gene of Leptospira borgpetersenii and the flaB2 gene of Serpulina (Treponema) byodysenteriae were sequenced and no promoter sequences were found (Mitchison et al., 1991; Koopman et al., 1993). No transcriptional start point has been determined for these genes, but when we examined the $f l a B 5^{\prime}$-noncoding region of $L$. borgpetersenii and $S$. byodysenteriae, we discovered a putative promoter sequence, 82 and $65 \mathrm{bp}$, respectively, upstream of the ATG start codon. These suggested promoter sequences are similar to both the $\sigma^{\mathrm{gp33-34}}$ promoter and the promoter sequences proposed here for the Borrelia fla genes (Table 2). This finding implies that the expression of the fla gene of Borrelia and the homologous flaB of Leptospira and Serpulina might be controlled by a $\sigma$ factor similar to $\sigma^{\text {gp33-34. }}$

\section{Sequence analysis of the deduced flagellar proteins}

The deduced translational products of the $f a$ gene from the different species were compared to the deduced translational product of $B$. burgdorferi $\mathrm{B} 31$. The comparison of the different flagellar proteins in an optimal alignment is shown in Fig. 3. The deduced flagellins of the Lyme disease genomic species, strains B31, HB19, ACAI and Ip90, were 336 amino acids long with a calculated molecular mass of $36960 \mathrm{Da}$, and the protein for $B$. crocidurae was 335 amino acids long with a molecular mass of $36850 \mathrm{Da}$. B. bermsii HS1 and B. anserina were 334 amino acids long with a molecular mass of $36740 \mathrm{Da}$. The Lyme borreliosis species were $94-95 \%$ identical to the relapsing fever species at the deduced amino acid level, compared to $85-86 \%$ at the DNA level. From the amino acid sequence comparison of the flagellar protein, it was evident that the $\mathrm{N}$ - and $\mathrm{C}$-terminal parts were conserved between different species, while central parts of the protein showed more sequence variation. This feature of having conserved $\mathrm{N}$ - and $\mathrm{C}$-terminal parts of the polypeptide chain and heterology in the central region has been observed in all sequenced flagellin proteins when comparing them either within the species or to related genera. Furthermore, N-terminal amino acid sequence comparisons of the B. burgdorfer $i$ flagellar protein revealed a remarkable similarity to the $\mathrm{N}$-terminal regions of class $\mathrm{B}$ (core) flagellin polypeptides from other spirochaetes (Gassmann et al., 1989b; Norris et al., 1993).

Fedorov \& Efimov (1990) proposed a model for the $E$. coli flagellin where the conserved regions, i.e. the terminal parts, are involved in flagellin export and flagellum assembly, whereas the variable middle region seems to be less important for the structure, and may therefore represent variable antigenic determinants. Results sup-

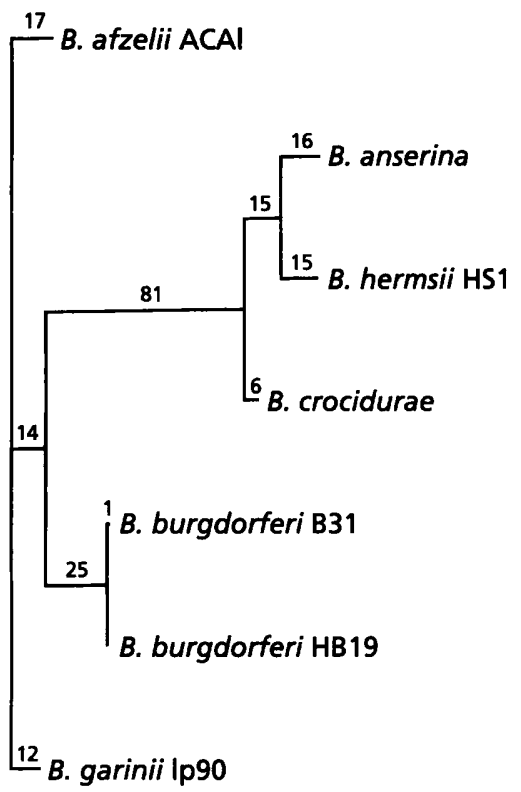

Fig. 4. Evolutionary relationship of the flagellar proteins between different relapsing fever borreliae, $B$. hermsii and $B$. crocidurae; Lyme borreliae, B. burgdorferi, B. afzelii and B. garinii; and the avian borreliosis agent $B$. anserina. The phylogenetic tree was derived from the parsimony analysis performed with the PAUP package. The numbers on each branch represent the unique characters (recognized by PAUP) that differ between the bars.

porting this model in Borrelia have been reported by different authors. Berland et al. (1991) reported that sera from 17 out of 18 patients with late-stage Lyme disease reacted with the variable middle part of the $f a$ gene product from B. burgdorferi strain N40. Furthermore, antisera against native or denatured flagellar proteins derived from different animal species immunized with $B$. burgdorferi $\mathrm{GeHo}$, reacted strongly with epitopes located in the variable domain of the flagellin, while cross-reactive antisera raised against Bacillus subtilis and $T$. phagedenis bound exclusively to the $\mathrm{N}$ - and C-terminal regions (Gassmann et al., 1991; Rasiah et al., 1992). A $14 \mathrm{kDa}$ fragment covering part of the variable domain (amino acids 131-266) does not cross-react with sera from Bacillus subtilis, E. coli, Proteus mirabilis, S. typhimurium and T. phagedenis (Rasiah et al., 1992).

\section{Evolutionary relationships}

The evolutionary relationships between the deduced flagellar proteins from the four Borrelia species were further investigated using the programs PAUP and PILEUP. These computer analyses revealed that the Lyme borreliosis genomic species were evolutionarily more closely related to each other than to the relapsing fever species or avian borreliosis species (Fig. 4). B. hermsii and $B$. anserina can be distinguished as a group distant from the Lyme disease species B. burgdorferi, B. afzelii and B. garinii. These results are in agreement with those obtained by Marconi \& Garon (1992a), who investigated the re- 
lationship between 16S rRNA sequences on the basis of signature or diagnostic nucleotide positions.

In the Lyme borreliae branch of the tree, the species delineation into three different groups can be clearly seen, which is in agreement with earlier reports (Baranton $e t$ al., 1992; Canica et al., 1993). Interestingly, the North American relapsing fever species $B$. bermsii is more closely related to the avian borreliosis species $B$. anserina than to $B$. crocidurae, which is a relapsing fever agent from West Africa; a likely explanation is that our study used $B$. hermsii and $B$. anserina isolated from North America. Therefore, these two species probably share some properties. The partial fla gene sequences (Picken, 1992) from the North American relapsing fever species $B$. turicatae and $B$. parkeri were grouped into the same branch as $B$. hermsii and $B$. anserina (data not shown).

The fact that the fla gene is highly conserved among the different Borrelia species makes the molecular studies, particularly nucleotide sequence analysis, an important tool for studies of evolution of Borrelia and also for practical use in the diagnosis of borreliosis in mammals and birds.

\section{ACKNOWLEDGEMENTS}

We thank Maria Jonsson for valuable discussions. This work was supported by grants from the Swedish Medical Research Council (Dnr 07922), the Swedish Board for Technological Development (Dnr 90-513), Lennanders foundation and NIH grant AI29731.

\section{REFERENCES}

Arnosti, D. N. \& Chamberlin, M. J. (1989). Secondary $\sigma$ factor controls transcription of flagellar and chemotaxis genes in Escherichia coli. Proc Natl Acad Sci US A 86, 830-834.

Åsbrink, E., Hovmark, A. \& Hederstedt, B. (1984). The spirochaetal etiology of acrodermatitis chronica atrophicans Herxheimer. Acta Dermatol Venereol 64, 506-512.

Baranton, G., Postic, D., Saint Girons, I., Boerlin, P., Piffaretti, J. C., Assous, M. \& Grimont, P. A. D. (1992). Delineation of Borrelia burgdorferi sensu stricto, Borrelia garinii sp. nov., and group VS 461 associated with Lyme borreliosis. Int J Syst Bacteriol 42, 378-383.

Barbour, A. G. (1984a). Isolation and cultivation of Lyme disease spirochetes. Yale J Biol Med 57, 521-525.

Barbour, A. G. (1984b). Immunochemical analysis of Lyme disease spirochetes. Yale J Biol Med 57, 581-586.

Barbour, A. G. (1988). Plasmid analysis of Borrelia burgdorferi, the Lyme disease agent. J Clin Microbiol 26, 475-478.

Barbour, A. G. \& Garon, C. F. (1987). Linear plasmids of the bacterium Borrelia burgdorferi have covalently closed ends. Science 237, 409-411.

Barbour, A. G., Hayes, S. F., Heiland, R. A., Schrumpf, M. E. \& Tessier, S. L. (1986). A Borrelia-specific monoclonal antibody binds to a flagellar epitope. Infect Immun 52, 549-554.

Bergström, S., Bundoc, V. G. \& Barbour, A. G. (1989). Molecular analysis of linear plasmid-encoded major surface proteins, OspA and OspB, of the Lyme disease spirochaete Borrelia burgdorferi. Mol Microbiol 3, 479-486.

Berland, R., Fikrig, E., Rahn, D., Hardin, J. \& Flavell, R. A. (1991). Molecular characterization of the humoral response to the 41- kilodalton flagellar antigen of Borrelia burgdorferi, the Lyme disease agent. Infect Immun 59, 3531-3535.

Brahamsha, B. \& Greenberg, E. P. (1989). Cloning and sequence analysis of $f a A$, a gene encoding a Spirocbaeta aurantia flagellar filament surface antigen. $J$ Bacteriol 171, 1692-1697.

Burman, N., Bergström, S., Restrepo, B. I. \& Barbour, A. G. (1990). The variable antigens Vmp7 and Vmp21 of the relapsing fever bacterium Borrelia bermsii are structurally analogous to the VSG proteins of the African trypanosome. Mol Microbiol 4, 1715-1726.

Canale-Parola, E. (1978). Motility and chemotaxis of spirochetes. Annu Rev Microbiol 32, 69-99.

Canica, M. M., Nato, F., du Merle, L., Mazie, J. C., Baranton, G. \& Postic, D. (1993). Monoclonal antibodies for identification of Borrelia afzelii sp. nov. associated with late cutaneous manifestations of Lyme borreliosis. Scand J Infect Dis 25, 441-448.

Champion, C. I., Miller, J. N., Lovett, M. A. \& Blanco, D. R. (1990). Cloning, sequencing, and expression of two class B endoflagellar genes of Treponema pallidum subsp. pallidum encoding the 34.5- and 31.0-kilodalton proteins. Infect Immun 58, 1697-1704.

Charon, N. W., Greenberg, E. P., Koopman, M. B. H. \& Limberger, R. J. (1992). Spirochete chemotaxis, motility, and the structure of the spirochetal periplasmic flagella. Res Microbiol 143, 597-603.

Costanzo, M., Brzustowicz, L., Hannett, N. \& Pero, J. (1984). Bacteriophage SP01 genes 33 and 34. Location and primary structure of genes encoding regulatory subunits of Bacillus subtilis RNA polymerase. $J$ Mol Biol 180, 533-547.

Craft, J. E., Fischer, D. K., Hardin, J. A., Garcia-Blanco, M. \& Steere, A. C. (1984). Spirochetal antigens in Lyme disease. Artbritis Rheum 27(suppl.), 64.

Craft, J. E., Fischer, D. K. \& Shimamoto, G. T. (1986). Antigens of Borrelia burgdorferi recognized during Lyme disease. J Clin Invest 78, 934-939.

Fedorov, O. V. \& Efimov, A. V. (1990). Flagellin as an object for supramolecular engineering. Protein Eng 3, 411-413.

von Gabain, A., Belasco, J. G., Schottel, J. L., Chang, A. C. Y. \& Cohen, S. N. (1983). Decay of mRNA in Escherichia coli: investigation of the fate of specific segments of transcripts. Proc Natl Acad Sci US A 80, 653-657.

Gassmann, G. S., Kramer, M., Göbel, U. B. \& Wallich, R. (1989a). Nucleotide sequence of a gene encoding the Borrelia burgdorferi flagellin. Nucleic Acids Res 17, 3590.

Gassmann, G. S., Deutzmann, R., Vogt, A. \& Göbel, U. B. (1989b). $\mathrm{N}$-terminal amino acid sequence of the Borrelia burgdorferi flagellin. FEMS Microbiol Lett 60, 101-106.

Gassmann, G. S., Jacobs, E., Deutzmann, R. \& Göbel, U. B. (1991). Analysis of the Borrelia burgdorferi GeHo fla gene and antigenic characterization of its gene product. J Bacteriol 173, 1452-1459.

Gilman, M. Z., Wiggs, J. L. \& Chamberlin, M. J. (1981). Nucleotide sequences of two Bacillus subtilis promoters used by Bacillus subtilis sigma-28 RNA polymerase. Nucleic Acids Res 9, 5991-6000.

Goldstein, S. F. \& Charon, N. W. (1988). Motility of the spirochete Leptospira. Cell Motil Cytoskeleton 9, 101-110.

Göransson, M., Forsman, K., Nilsson, P. \& Uhlin, B. E. (1989). Upstream activating sequences that are shared by two divergently transcribed operons mediate cAMP-CRP regulation of pilusadhesin in Eschericbia coli. Mol Microbiol 3, 1557-1565.

Gyllensten, U. B. \& Erlich, H. A. (1988). Generation of singlestranded DNA by the polymerase chain reaction and its application to direct sequencing of the HLA-DQA locus. Proc Natl Acad $S_{c i}$ US $A$ 85, 7652-7656.

Hamlyn, P. H., Gait, M. J. \& Milstein, C. (1981). Complete sequence 
of an immunoglobulin mRNA using specific priming and the dideoxynucleotide method of RNA sequencing. Nucleic Acids Res 9, 4485-4492.

Harr, R., Fällman, P., Häggström, M., Wahlström, L. \& Gustafsson, P. (1986). GENEUS, a computer system for DNA and protein sequence analysis containing an information retrieval system for the EMBL data library. Nucleic Acids Res 14, 273-284.

Helmann, J. D. (1991). Alternative sigma factors and the regulation of flagellar gene expression. Mol Microbiol 5, 2875-2882.

Helmann, J. D. \& Chamberlin, M. J. (1987). DNA sequence analysis suggests that expression of flagellar and chemotaxis genes in Escherichia coli and Salmonella typhimurium is controlled by an alternative $\sigma$ factor. Proc Natl Acad Sci US A 84, 6422-6424.

Holt, S. C. (1978). Anatomy and chemistry of Spirochetes. Microbiol Rev 42, 114-160.

Howe, T. R., Mayer, L. W. \& Barbour, A. G. (1985). A single recombinant plasmid expressing two major outer surface proteins of the Lyme disease spirochete. Science 227, 645-646.

Isaacs, R. D. \& Radolf, J. D. (1990). Expression in Escherichia coli of the 37-kilodalton endoflagellar sheath protein of Treponema pallidum by use of the polymerase chain reaction and a T7 expression system. Infect Immun 58, 2025-2034.

Isaacs, R. D., Hanke, J. H., Guzman-Verduzco, L.-M., Newport, G., Agabian, N., Norgard, M. V., Lukehart, S. A. \& Radolf, J. D. (1989). Molecular cloning and DNA sequence analysis of the 37-kilodalton endoflagellar sheath protein gene of Treponema pallidum. Infect Immun 57, 3403-3411.

Johnson, W. C., Moran, C. P., Jr \& Losick, R. (1983). Two RNA polymerase sigma factors from Bacillus subtilis discriminate between overlapping promoters for a developmentally regulated gene. Nature 302, 800-804.

Jonsson, M., Noppa, L., Barbour, A. G. \& Bergström, S. (1992). Heterogeneity of outer membrane proteins in Borrelia burgdorferi: comparison of osp operons of three isolates of different geographic origins. Infect Immun 60, 1845-1853.

Koopman, M. B. H., de Leeuw, O. S., Bernard, A. M., van der Zeijst, B. A. \& Kusters, J. G. (1992). Cloning and DNA sequence analysis of Serpulina (Treponema) byodysenteriae gene encoding a periplasmic flagellar sheath protein. Infect Immun 60, 2920-2925.

Koopman, M. B. H., Baats, E., de Leeuw, O. S., van der Zeijst, B. A. \& Kusters, J. G. (1993). Molecular analysis of a flagellar core protein gene of Serpulina (Treponema) byodysenteriae. J Gen Microbiol 139, 1701-1706.

Limberger, R. J., Slivienski, L. L., Yelton, D. B. \& Charon, N. W. (1992). Molecular genetic analysis of a class $B$ periplasmic-flagellum gene of Treponema phagedenis. J Bacteriol 174, 6404-6410.

Malloy, D. C., Nauman, R. K. \& Paxton, H. (1990). Detection of Borrelia burgdorferi using the polymerase chain reaction. $J$ Clin Microbiol 28, 1089-1093.

Maniatis, T., Fritsch, E. F. \& Sambrook, J. (1982). Molecular Cloning: a Laboratory Manual. Cold Spring Harbor, NY: Cold Spring Harbor Laboratory.

Marconi, R. T. \& Garon, C. F. (1992a). Phylogenetic analysis of the genus Borrelia: a comparison of North American and European isolates of Borrelia burgdorferi. J Bacteriol 174, 241-244.
Marconi, R. T. \& Garon, C. F. (1992b). Development of polymerase chain reaction primer sets for diagnosis of Lyme disease and for species-specific identification of Lyme disease isolates by $16 \mathrm{~S}$ rRNA signature nucleotide analysis. J Clin Microbiol 30, 2830-2834.

Mitchison, M., Rood, J. I., Faine, S. \& Adler, B. (1991). Molecular analysis of a Leptospira borgpetersenii gene encoding an endoflagellar subunit protein. J Gen Microbiol 137, 1529-1536.

Norris, S. J. \& the Treponema pallidum polypeptide research group. (1993). Polypeptides of Treponema pallidum: progress toward understanding their structural, functional, and immunologic roles. Microbiol Rev 57, 750-779.

Olsén, B., Jaenson, T. G. T., Noppa, L., Bunikis, J. \& Bergström, S. (1993). A Lyme borreliosis cycle in seabirds and Ixodes uriae ticks. Nature 362, 340-342.

Pallesen, L. \& Hindersson, P. (1989). Cloning and sequencing of a Treponema pallidum gene encoding a 31.3-kilodalton endoflagellar subunit (FlaB2). Infect Immun 57, 2166-2172.

Parales, J., Jr \& Greenberg, E. P. (1993). Analysis of the Spirochaeta aurantia fla $A$ gene and transcript. FEMS Microbiol Lett 106, 245-252.

Picken, R. N. (1992). Polymerase chain reaction primers and probes derived from flagellin gene sequences for specific detection of the agents of Lyme disease and North American relapsing fever. J Clin Microbiol 30, 99-114.

Rasiah, C., Schiltz, E., Reichert, J. \& Vogt, A. (1992). Purification and characterization of a tryptic peptide of Borrelia burgdorferi flagellin, which reduces cross-reactivity in immunoblots and ELISA. $J$ Gen Microbiol 138, 147-154.

Rosa, P. A. \& Schwan, T. G. (1989). A specific and sensitive assay for the Lyme disease spirochete Borrelia burgdorferi using the polymerase chain reaction. J Infect Dis 160, 1018-1029.

Rosa, P. A., Hogan, D. \& Schwan, T. G. (1991). Polymerase chain reaction analyses identify two distinct classes of Borrelia burgdorferi. $J$ Clin Microbiol 29, 524-532.

Sadziene, A., Thomas, D. D., Bundoc, V. G., Holt, S. C. \& Barbour, A. G. (1991). A flagella-less mutant of Borrelia burgdorferi. Structural, molecular, and in vitro functional characterization. J Clin Invest $\mathbf{8 8}$, 82-92.

Sanger, F., Nicklen, S. \& Coulson, A. R. (1971). DNA sequencing with chain-terminating inhibitors. Proc Natl Acad Sci USA 74, 5463-5467.

Saunders, S. E. \& Burke, J. F. (1990). Rapid isolation of miniprep DNA for double strand sequencing. Nucleic Acids Res 18, 4948.

Swofford, D. (1990). PAUP: phylogenetic analysis using parsimony, version 3.0. Computer program distributed by the Illinois Natural History Survey, Champaign.

Wallich, R., Moter, S. E., Simon, M. M., Ebnet, K., Heiberger, A. \& Kramer, M. D. (1990). The Borrelia burgdorferi flagellum-associated 41-kilodalton antigen (flagellin): molecular cloning, expression, and amplification of the gene. Infect Immun 58, 1711-1719.

Woese, C. R. (1987). Bacterial evolution. Microbiol Rev 51, 221-227.

Zhu, J., Kempenaers, W., Van der Straeten, D., Contreras, R. \& Fiers, W. (1985). A method for fast and pure DNA elution from agarose gels by centrifugal filtration. Biotechnology 3, 1014-1016.

Received 11 April 1994; revised 5 August 1994; accepted 18 August 1994. 